\title{
Agradecimentos da Editoria
}

\author{
Isabela Machado da Silva \\ Cláudio Vaz Torres \\ Universidade de Brasilia
}

A Editoria da Revista Psicologia: Teoria e Pesquisa agradece a inestimável contribuição dos editores associados convidados, que viabilizaram a publicação deste número: Adriana Wagner (UFRGS), Andrea Zanella (UFSC), Andreia Schmidt (USP), Angélica Bastos (UFRJ), Denise Falcke (UNISINOS), Edson M. Huziwara (UFMG), Inês Catão (Hospital da Criança de Brasília), Jean Von Hohendorff (IMED, Passo Fundo), Lisiane Bizarro (UFRGS), Livia Moretto (USP), Maria Cicilia de Carvalho Ribas (UFPE), Maria Luisa Mendes Teixeira (Universidade Presbiteriana Mackenzie), Maria Lyra (UFPE), Marilene Proença (USP),
Rafael Pecly Wolter (UERJ), Roberto Cruz (UFSC), Sônia Regina P. Fernandes (UFBA), Verônica Bender Haydu (UEL) e Thiago Gomes de Castro (UFRGS). Nossos agradecimentos também à direção do Instituto de Psicologia da UnB (IP) e às coordenadoras dos programas de pós-graduação do IP, que nos ajudaram a planejar este número especial e a executá-lo.

Por fim, aproveitamos a oportunidade para agradecer pelo profissionalismo e pelo excelente trabalho desempenhado pela FINATEC, pela Foco Digital, responsável pela diagramação dos artigos, e pela Empório das Letras, que nos auxiliou com a revisão e a tradução dos manuscritos.

Esperamos que todos aproveitem a leitura! 